\title{
MISCELÁNEA
}

\section{EL ABAD DE RUTE Y UNA CARTA DE IOPE}

En el Archivo del Instituto de Valencia de Don Juan, 38, III, II2, se conservan dos cartas autógrafas de Lope. Las publicó hace ya cincuenta años el ilustre lopista José $F$. Montesinos en la $R F E$, Ig22, IX, pp. 323-326. La primera, escrita en latín y dirigida al Papa Urbano VIII pudo fecharla en I627; la respuesta del Cardenal Barberini, en que agradece a Lope su obediencia, buenos deseos y ofrecimientos, es de diciembre de ese año. Así, Agrustín G. de Amezúa la sitúa en su monumental edición del epistolario del Fénix entre setienbre y octubre.

La segunda, dirigida al Duque de Sessa, dice así:

I a carta de la Arellano, yo la tengo, que por ocasión destas fiestas del Corpus la suspendi, pareziéndome no ynportaba. La carta de Córdoua yrá otro ordinario, porque es justo que $v$. ex ${ }^{2}$. responda como quien ha visto el libro; y ni ha de ser tan presto que él lo dude, ni con tan poco acuerdo que no crea que se entiende. V. ex. ${ }^{2}$ perdone la escusa, si se lo parece, que parte tiene desto la ocupación. Guarde Dios a v. ex. ${ }^{\text {s }}$ los años que yo le pido y deseo. De casa.

Esta carta fue, sin duda, desgajada del volumen en que se encontraba en el Archivo de Altamira hasta el siglo pasado. Allí estaba en I863, cuando D. Isidoro Rosell hizo su copia; de ésta pasó a la de Fernández-Guerra. Amezúa la publicó con el número I97 en su edición, tomo III, p. I92.

Como se ve, no lleva fecha. Montesinos no propuso ninguna ni pudo dar razón de las personas aludidas en ella. Sin embargo, Amezúa da con cierta seguridad la de "Toledo, I8-22 de junio de I6I5"; ya en su página IXVIII había indicado que hacía las fechaciones upor simple conjetura», teniendo en cuenta la "proximidad y convivencia material en el códice con cartas de años indubitados». La solución parece razonable y probablemente, en este caso, tuvo en cuenta la referencia a la fiesta del Corpus; ello le indujo a asignarle como lugar Toledo.

De ahí a darle el año I6r5 y los días I8 a 22 de junio no había más que un paso, pues en la Imperial Ciudad estaba Lope aquella primavera 
y tal fiesta cayó el I8. Aunque la cita del Corpus no obliga a localizarla necesariamente en Toledo, es lógico que así sea, ya que Lope promete enviar en "otro ordinarion la epistola del Córdoba; la referencia al correo indica que Lope y Sessa no estaban, desde luego, en la misma ciudad.

Creo que los nombres de Arellano y Córdoba permiten mayores precisiones. Il primero en el texto autógrafo es una mujer: «La carta de la Arellano yo la tengon, dice, aunque Amezúa imprime sin el la original. Pensando en esa fórnula expresiva familiar y en la intervención del Fénix en los amoríos del Duque, nada tendría de extraño que se tratase de alguna aventura. Es verdad que en I6I5 Sessa estaba enredado con Jacinta y que la crisis, no definitiva, es ya de I6I6; pero, dado su carácter, es inútil pensar que sólo entonces pudiera surgir un nuevo amorío. En todo caso, la carta de la Arellano se retrasó, fuera - no así (y perdone ella el mal pensamiento si ocurrió lo primero).

"No puedo decir quién es ese Córdoba, hacia cuyo libro tan poca curiosidad sentía el Fénix, ni adivinar, claro está, de qué clase era tal obra». Esto dice Montesinos, y apunta a un Dr. Córdoba, citado en El laurel de Apolo. Creo, por mi parte, que la persona a quien Lope se refiere es $\mathrm{D}$. Friancisco Irernández de Córdoba, el famoso Abad de Rute, y la obra, la titulada Didascalia multiplex, publicada en Iyon en I6I5 ${ }^{1}$. La razón para pensarlo así -aparte el hecho normal en la época de decir Córdoba y no Fernández de Córdoba- es que tal libro va dedicado precisamente al Duque por el autor, su pariente. Lo que dice Lope quedaría así más claro: Sessa ha recibido un ejemplar de la obra pomposamente dedicada; el autor espera tal vez alguna generosidad de su rico familiar y no es imposible que la lograra; pero, salvo el dinero, es seguro que a D. Luis nada le preocupaba el contenido de esta obra humanistica, miscelánea de ensayos, desgraciadamente escrita en latín. Obsérvese que Lope insiste en que la respuesta ha de ser meditada, sin prisas, para que el inocente autor crea que se ha visto (esto es, que se ha leído) y que se entiende. Sólo a un erudito libro latino pueden convenir estos extremos. Bien lo advirtió Sessa, subrayando estas frases ${ }^{2}$. De haber estado en claro romance, él hubiera podido opinar algo personalmente, encargando a Lope ponerlo en pie. Pero no; Sessa no ha visto el libro; insisto en que ello indica que no lo ha lefdo, porque verlo sin duda que

1 Francisci Fernandii de Cordova Cordvbensis Didascalia Multiplex. Nunc primum in lucem enissa. Cvm qvinque indicibvs necessariis. Ivgdvni, Sumptibus Horatij Cardon. M. DCrv. Cvm privilegio regis.

2 Desde "porque es juston hasta wo crea que se entienden. Para Amezúa los subrayados, frecuentes en las cartas, son de Sessa. 
lo vio. Si, hay ironía en las palabras de. Lope, quien hubo al menos de ojear aquellas páginas para poder borrajear la respuesta. ¿Quién mejor para opinar de erudición clásica que él, que tanto presume siempre de ella? Es secretario para todo: hasta para hacer como que lee los libros que tampoco lee su señor. Distraído con las fiestas, Lope habla olvidado su obligación; pero hábil y rápido en sus reacciones, a la prisa de Sessa responde; allá va esa esquelilla con dos pretextos razonables. Adelante.

Poco le hubiera gustado al bueno de D. Francisco saber lo que se traían entre manos los dos amigos. Es indudable que esta su primera obra impresa le ilusionaba muchísimo y que había hablado de ello a sus conocidos. Góngora, compañero de cabildo, en carta desde Córdoba de I8 de junio de I6I4, dirigida a Tamayo de Vargas, la cita como de aparición inminente: "ya se nos está vinierido a los ojos, digo estampando en Francial; seguramente la conocía manuscrita cuando se anticipaba a decir de su autor que "sabe tanto de todo»; pues de todo habla el libro que anuncia y no sólo de poesía; de este saber ya tenía Góngora bastante noticia por la muestra del parecer de D. Francisco sobre sus Soledades; en él citaba ya su propio libro y se lo ponía a D. Luis como ejemplo: si por consejo de los amigos que lo vieron corrigió y modificó, lo mismo debía esperarse del poeta y su poema, dando pruebas de modestia de esa manera.

Modestamente también habla él otra vez en su dedicatoria al Duque de Sessa. Ya Amezúa la comentó, juzgándola como «elegante», noble y reposada». Sí, y además terriblemente lisonjera. Agradecido al Duque D. Antonio, el padre, "par est - dice al hijo- ut tibi paternarum non actionum modo, et fortunarum, sed virtutum etiam haeredi quantulamcunque valeam, referam semper. Accipe igitur libens hunc quem offero Didascaliae librumy. Pondera aquellas virtudes, entre las que están la liberalidad y el patrocinio de las musas, que sin duda D. Francisco esperaba. Iapidariamente, termina con un ruego: "Interim D.O.M. incolumen te nobis, ac patriae servet Hispaniae decus". El decoro de España holgazaneaba, en tanto, desdeñoso, o se afanaba por Floras y Jacintas, y su secretario vivía más atento también a amores y versos en romance que a viejas citas clásicas.

I a fecha del libro, sin embargo, puede plantear algunos problemas si la carta que comento se refiere efectivamente al Abad de Rute. La tasa lleva la fecha de $I 6$ de julio de I6I5. Resulta, pues, imposible que Lope hable de él un mes antes. ¿Será la carta de 26 de mayo - Corpusdel año r6r6? Podría ser; el libro pudo tardar en salir de. Lyon, llegar a D. Francisco y ser cnviado a su anhelado mecenas, que precisamente había estado de viaje entre octubre y diciembre de I6I5, en el cortejo 
de Lerma con ocasión de las bodas de los principes. Lope fue con él. En cualquier caso, la carta indica que el libro se había recibido hacía poco. Como Amezúa no llegó a publicar sus comentarios, no podemos saber si logró identificar al aludido Córdoba, cosa que no creo. Pero situar la carta en I6I6 obligaría a llevar a Lope a Toledo, cuando resulta poco probable, o a alejar a Sessa de Madrid.

Parece aconsejable buscar otra solución. Es posible, por lo pronto, que el libro, muy lentamente impreso, pues ya estaba preparado para la preusa en I6II, con elogios y censuras de $16 \mathrm{I} 2$ y I6I3, estuviera prácticamente acabado en I6r4. La cita de Góngora lo sitúa como inmediato. Es más: en la portada de un ejemplar de la Biblioteca Universitaria de Granada, una mano de la época escribió dos cosas; una, arriba: "Del Col.o de la comp. de JHS de Gran. an; y otra, bajo la fecha 3rDCXV: "Impreso el año de I6r4". Sigue, en papel claramente distinto al de todo el volumen, la suma del privilegio, la tasa citada y las erratas firmadas por Murcia de la Llana, cuatro páginas en total, que debieron de imprimirse ya en España. Teniendo en cuenta que los elogiantes del libro, cu prosa o verso, son más de uno de dicha Orden y que el propio $D$. Irancisco en el parecer sobre las Solcdades declara lo mismo al escribir que ule vieron muchos Padres de la Compañian y especialmente el $P$. Juan Luis de la Cerda, parece que alli debían saber bien cuándo se inprimió ${ }^{1}$. El autor esperaría impaciente los permisos franceses (entre octubre y noviembre de I6I4); no bien recibidos, se imprimieron y se hizo la portada con la fecha ya del año siguiente. El libro vino en seguida a España y se vendieron algunos ejemplares, aún sin tasa. Uno de ellos fue el que se envió a Sessa. Que así fue todo, lo prueba sin duda otro ejemplar (que fue del Colegio Mayor de Santa Cruz y Santa Catalina), conservado en la misma Biblioteca de Granada: carece de la doble hoja donde consta la tasa de julio de I6I5. Resulta, así, que a la misma Granada llegó mucho antes de esa fecha. Los jesuítas, por el contrario, adquitieron más tarde un ejemplar que venía completo y por ello el atento comprador o bibliotecario se apresuró a indicar la fecha de impresión, que él bien sabía ${ }^{2}$.

De esta manera encajan todos los datos sobre el libro en cuestión: la referencia en el parecer del propio Abad, la carta de Góngora algo

1 El parecer, descubierto, publicado y comentado por EMmro Orozco DiAz, puede verse en su libro En torno a las "Soledades» de Góngora, Granada I969, pp. I30-145.

- En el ángulo superior derecho y de la misma mano hay dos mayúsculas: BS. ¿Las iniciales del P. Benito Sojo, uno de los elogiantes en verso latino?. 
posterior $y$, finalmente, la de Lope. Todo en torno a esta obra hoy olvidada que $D$. Francisco dedicó a Sessa con ingenuidad manifiesta. $O$ tal vez no. Se colocaba así entre Lope y Góngora: en el Examen del Antidoto, hacia I6I6, volvía a citar su Didascalia e incluía al Duque en el bando gongorino. No es de extrañar que Lope, conocedor indudable de la opinión ya expresada en el parecer y probablemente fuera de él, prestara tan poca atención -la guerra ha comenzado- a tan serio y algo aburrido libro, en el que su autor había puesto tantas esperanzas.

Nicolas Marín 